\title{
Vulvar Superficial Myofibroblastoma
}

National Cancer Institute

\section{Source}

National Cancer Institute. Vulvar Superficial Myofibroblastoma. NCI Thesaurus. Code C128272.

An uncommon benign polypoid or nodular mesenchymal neoplasm that arises in the vulvovaginal region. It is characterized by the presence of oval or spindle-shaped cells in a collagenous stroma and is separated from the epidermis by a variably thick Grenz zone. 